\title{
Long-term stability of cellulose acetate butyrate thin films for nuclear certified reference materials
}

\author{
Renáta Buják ${ }^{1}$ (1) Laurens Delva ${ }^{2} \cdot$ Mustafa Erkoç $^{2} \cdot$ Jeroen Bauwens $^{1} \cdot$ \\ Rožle Jakopič $^{1} \cdot$ Laszlo Vincze $^{3} \cdot$ Yetunde Aregbe $^{1} \cdot$ Ludwig Cardon $^{2}$
}

Received: 26 August 2016/Published online: 27 October 2016

(c) The Author(s) 2016. This article is published with open access at Springerlink.com

\begin{abstract}
Characterization of cellulose acetate butyrate (CAB) thin films with 17, 35 and $52 \mathrm{wt} \%$ butyryl is carried out to select the most suitable matrix material for the $U$ and $\mathrm{Pu}$ containing large-sized dried spike reference material. The virgin $C A B$ samples were aged by vibrations, heat, humidity, UV light and X-rays. Characterization was done by thermoanalytical techniques, gel permeation chromatography, mechanical tests and via Rayleigh and Compton scattering. The results show that $\mathrm{CAB}$ with lower butyryl content can withstand higher operational temperatures and has greater mechanical strength while $\mathrm{CAB}$ with higher butyryl content seems to be more resistant to radiation.
\end{abstract}

Keywords Nuclear safeguards · Cellulose acetate butyrate $\cdot$ Ageing $\cdot$ Large-sized dried spike $\cdot$ Uranium · Plutonium

\section{Introduction}

Large-sized dried spike containing uranium and plutonium are essential part of the nuclear material accountancy for safeguards purposes. The Treaty on Non-Proliferation of

Renáta Buják

renata.bujak@ec.europa.eu

1 Directorate G: Nuclear Safety \& Security, Joint Research Centre, European Commission, Retieseweg 111, 2440 Geel, Belgium

2 Centre for Polymer \& Material Technologies (CPMT), Faculty of Engineering and Architecture, Ghent University, Technologiepark 915, 9052 Zwijnaarde, Belgium

3 Department of Analytical Chemistry, Faculty of Sciences, Ghent University, Krijgslaan 281, S12, 9000 Ghent, Belgium
Nuclear Weapons and the EURATOM Treaty require the signatory states to provide detailed accounting records for their fissile materials $[1,2]$. The aim of nuclear safeguards is the verification of fissile material for its intended and declared peaceful use. This involves accurate measurements of uranium and plutonium amount content and isotopic composition of spent fuel solution at reprocessing plants. The IRMM-1027 large-sized dried (LSD) spikes are tailor-made certified reference materials (CRMs) that are designed for such purposes [3]. The LSD spikes are produced exclusively by JRC-Geel and the International Atomic Energy Agency in Vienna. The production is on a small laboratory scale at the JRC-Geel site and every year 1200 units are prepared. The starting materials are high purity $\mathrm{U}$ and $\mathrm{Pu}$ metals, which are either natural (U) or isotopically enriched $(\mathrm{U}, \mathrm{Pu})$ [4]. Each individual spike contains about $50 \mathrm{mg}$ uranium $\left(m\left({ }^{235} \mathrm{U}\right) / m(\mathrm{U}) \sim 20 \%\right)$ and $1.8 \mathrm{mg}$ plutonium $\left(m\left({ }^{239} \mathrm{Pu}\right) / m(\mathrm{Pu}) \sim 98 \%\right)$ in dried nitrate form, allowing the undiluted spent fuel solution to be added quantitatively to them. The measurements are carried out with Isotope Dilution Thermal Ionization Mass Spectrometry (ID-TIMS) by plant operators and safeguards authorities by the European Commission and also outside EU [5]. The uncertainty that is introduced by this reference material is very low, and allows the laboratories to achieve IDMS measurements results with uncertainties below the target value of $0.28 \%$ for hot-cell conditions, expressed as a relative standard uncertainty $[6,7]$.

In the past, batches of LSD spikes were used within a short period of time, approximately half a year or 1 year. The demand of the market however has been changed during the last decade. Additionally, the availability of the precious and scarce high purity and enriched $\mathrm{Pu}-239$ reference metal is limited, so the long term stability of the LSD spikes became crucial for the producer as well as for 
the customers. The IRMM-1027 series of LSD spikes are prepared in penicillin glass vials to allow them to be gripped and moved with manipulators inside the hot-cells. For storage and transport purposes, the solid uranyl and plutonium nitrate are fixed at the bottom of the vial with an organic coating, which serves also as a supporting matrix for the spikes. There are stringent requirements for this coating material deposited onto the U/Pu solid spikes: it should be readily dissolved in hot $\mathrm{HNO}_{3}$; it should preferentially be an organic compound without halogens; it should be resistant to radiolysis - or at least should not degrade within the timeframe of the validity of the certificate; it should adhere well to glass; it should be easy to handle and dispense; it should not cause interference with the IDMS measurements and it should have sufficient mechanical strength. During the 1990s, tetrahydrofuran (THF) was applied as coating which formed stable complexes with $\mathrm{U}$ and $\mathrm{Pu}$ but it required a long and complex dissolution procedure [8]. Customers' feedback at the time showed that they preferred a spike that could be easily dissolved and used. Cellulose acetate butyrate (CAB) was therefore chosen as a 'LSD producer-' and 'LSD customer'-friendly alternative for THF [9]. Cellulose esters are widley use in the industy as coatings, plastics, membranes [10], and particularly $\mathrm{CAB}$ is also used as nuclear track detector [11]. CAB is an ester of cellulose that comes with different acetyl and butyryl substitution of hydroxyl groups (see Fig. 1).

This substitution is usually expressed in wt $\%$ as approximate content of the corresponding group at the triester of the pyranose ring. The properties of $\mathrm{CAB}$ depend on the degree of substitution: usually the higher the butyryl content the higher the flexibility and the chemical resistance. In the literature, several studies can be found on the thermal degradation, on the mechanical properties, on the degradation due to irradiation of cellulose and cellulose derivatives [11, 13-16, 13-16] However, so far no research paper can be found which deals with the application of cellulose acetate butyrate on nuclear materials as a thin film coating aiming to understand the complex degradation behaviour caused by heat, radiation and vibrations. The main objective of this study was to characterize before and
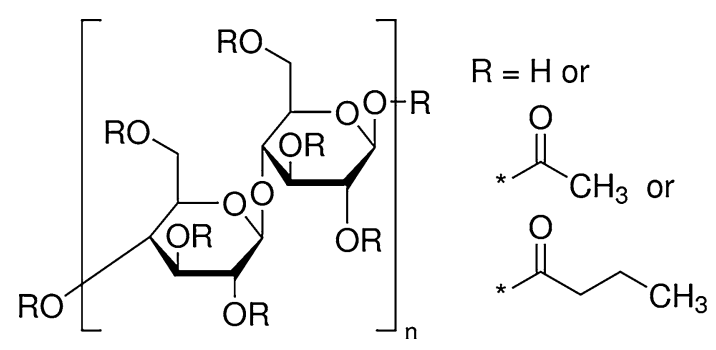

Fig. 1 Chemical structure of cellulose acetate butyrate [12] after ageing and to compare the degradation behaviour of three commercially available CABs in order to find the best appropriate butyryl substitution for the IRMM 1027 LSD spike application. CAB with $17 \mathrm{wt} \%$ butyryl content was successfully used on the initial investigations with metallic spikes as well as on the LSD spikes [17]. However, there are only empirical data available concerning the life time of the $\mathrm{CAB}$ with $17 \mathrm{wt} \%$ butyryl substitution which shows that this layer tends to chip and flake off after about 2 years of storage. This does not meet anymore the current demand from the end-users to extend the life time of the LSD spikes beyond 2 years. Empirical studies at JRC-Geel already showed that $\mathrm{CAB}$ with $35 \mathrm{wt} \%$ butyryl applied on $\mathrm{U} / \mathrm{Pu}$ LSD spikes preserved the integrity of the spike for more than 3 years. Hence, our aim was to find the best suitable butyryl substitution of CAB for future IRMM-1027 LSD spikes that complies with all the above mentioned criteria.

In the current paper, the preparation procedure of the $\mathrm{CAB}$ layer on LSD spikes is presented and the thermal, chemical and mechanical properties of the virgin and aged polymers without uranyl- and $\mathrm{Pu}$-nitrate were investigated. Three commercially available CABs were tested: 17-19 wt\% (CAB-17) as the lowest butyryl substitution, 35-39 $\mathrm{wt} \%(\mathrm{CAB}-35)$ as an intermediate butyryl substitution and $52 \mathrm{wt} \%$ (CAB-52) as the highest available butyryl substitution. The physical and chemical degradation were investigated by carrying out transport and ageing tests. The chemical ageing was accelerated by humidity, temperature, UV and X-ray irradiation. Both the virgin and aged thin films were characterized by thermogravimetry analysis (TGA), differential scanning calorimetry (DSC), gel permeation chromatography (GPC), micro-X-ray fluorescence (XRF) and by tensile testing. The different ageing experiments were carried out independently, thus the combination of these are not part of our study. However, in reality the samples are under constant irradiation; and the exposure to variation of temperature, UV light and vibrations are happening mostly during transport.

\section{Experimental}

CAB with 17 wt $\%$ butyryl content was purchased from Sigma-Aldrich, CAB with 35 wt\% butyryl from Acrōs while $\mathrm{CAB}$ with $52 \mathrm{wt} \%$ butyryl was acquired from Eastman Chemicals. The properties of the three different CABs are shown in Table 1. The thin film samples were prepared by evaporating the solvent from the $10 \mathrm{wt} \% \mathrm{CAB}$ solution prepared in acetone. There were two types of thin film samples, one type prepared in the original penicillin vial and the other in a Teflon mould. The latter was prepared by pouring and spreading the solution into the mould 
Table 1 Properties of the cellulose acetate butyrate as supplied by the manufacturer

\begin{tabular}{lllll}
\hline & $M_{\mathrm{n}}\left(\mathrm{g} \mathrm{mol}^{-1}\right)$ & Butyryl content $(\mathrm{wt} \%)$ & Acetyl content $(\mathrm{wt} \%)$ & Hydroxyl content $(\mathrm{wt} \%)$ \\
\hline CAB-17 & 65,000 & $16.5-19.0$ & $28.0-31.0$ & $0.8-1.4$ \\
CAB-35 & 70,000 & $35.0-39.0$ & $12.0-15.0$ & 1.8 \\
CAB-52 & 30,000 & 52.0 & 2.0 & 1.8 \\
\hline
\end{tabular}

obtaining thin film rectangular samples after evaporation of the solvent. The dimensions of the rectangular samples were as follows: width $10 \mathrm{~mm}$, thickness approximately $0.2 \mathrm{~mm}$ and length $150 \mathrm{~mm}$.

The rectangular samples could then be cut into the desired sample form using a scalpel. For the transport tests, $\mathrm{Mg}\left(\mathrm{NO}_{3}\right)_{2} \times 6 \mathrm{H}_{2} \mathrm{O}$ was used as an inactive replacement salt of the $\mathrm{U}$ and Pu-nitrates. First, $2.5 \mathrm{~mL}$ solution of 2 wt $\% \mathrm{Mg}\left(\mathrm{NO}_{3}\right)_{2}$ in $5 \mathrm{~mol} \mathrm{~L}^{-1} \mathrm{HNO}_{3}$ was dispensed into the vials and evaporated. Then, $0.7 \mathrm{~mL} 10 \mathrm{wt} \% \mathrm{CAB}$ solution in acetone was applied and evaporated to create a similar structure to that found in the spike material.

\section{Transport simulations}

The samples were handled in the same manner as the real LSD spikes. After the preparation of the CAB with the magnesium nitrate salt in the penicillin vials, they were closed with a silicon cap and placed into PVC bags. The bags were sealed individually and put into a type EMMA container filled with expanded polystyrene. This container was then placed on the transport simulator. The standard used for simulating the transport by plane was the International Safe Transit Association (ISTA) air (60 min/run, $200 \mathrm{~Hz}$ ). The total simulation consisted of real transport by car and simulations by truck and airplane. The transport simulations run for 1,2 and $3 \mathrm{~h}$. At each time, visual inspection was made to check whether the coating was intact.

\section{UV light irradiation}

The UV xenon test was performed on a Xenon test 1200 apparatus according to ISO 4892, method A [18]. Chamber temperature and relative humidity were controlled at $38 \pm 3{ }^{\circ} \mathrm{C}$ and $50 \pm 10 \%$ respectively. The test was performed using both the rectangular thin film samples and the glass vials. Both types of samples were packed and sealed in PVC bags. Samples were evaluated at $1000 \mathrm{~h}-$ approximating to 1 year of weathering conditions-and at $2000 \mathrm{~h}$ - to 2 years of weathering conditions.

\section{X-ray irradiation}

The degradation through time of the different types of $\mathrm{CAB}$ was monitored by applying a focused, monochromatic
$17.4 \mathrm{keV}$ X-ray beam. The X-ray source was an Xbeam (X-ray Optical Systems Inc., Albany, NY, USA) microfocus tube equipped with a doubly curved crystal optic for focusing and monochromatisation. The sample of $100 \times 100 \mu \mathrm{m}$ was attached to an aluminium plate by a transparent Scotch tape. The X-ray tube was operated at $40 \mathrm{kV}, 0.800 \mathrm{~mA}$, the spot size was $\approx 150(\mathrm{H}) \times 50$ (V) $\mu \mathrm{m}^{2}$ full width at half maximum, single spot measurement and the Compton and Rayleigh scatter spectra were saved every $1000 \mathrm{~s}$ real time.

\section{Thermogravimetric analysis (TGA)}

The TGA measurements were carried out with a Netzsch 449 F3 Jupiter type analyser. Approximately $20 \mathrm{mg}$ of the samples were placed in a Pt-Rh crucible and heated up to $600{ }^{\circ} \mathrm{C}$ with a heating rate of $10{ }^{\circ} \mathrm{C} \mathrm{min}-1$ in nitrogen atmosphere. The mass changes were recorded with time and with increasing temperature. Only the virgin samples were tested.

\section{Differential scanning calorimetry (DSC)}

DSC measurements were performed on a Netzsch DSC 204 F1. Aluminium crucibles were used and the experiments were run under an inert nitrogen atmosphere $\left(20 \mathrm{~mL} \mathrm{~min}{ }^{-1}\right)$. A heating/cooling programme between 25 and $280{ }^{\circ} \mathrm{C}$ with a scanning rate of $10{ }^{\circ} \mathrm{C} \min ^{-1}$ was applied. Approximately $20 \mathrm{mg}$ of sample material was used. The glass transition temperature and melting temperature were measured for the three different types of $\mathrm{CAB}$ thin films. Only the virgin samples were tested.

\section{Gel permeation chromatography (GPC)}

GPC was used as a direct way to measure degradation by determining the molecular weight of the samples. GPC measurements were performed on a Waters Instrument, with RI detector (2414 Waters), equipped with three Polymer Standards Services GPC serial columns (1x GRAM Analytical $30 \AA, 10 \mu \mathrm{m}$ and $2 \times$ GRAM Analytical $1000 \AA, 10 \mu \mathrm{m})$. Polystyrene standards were used for calibration. The CAB films were dissolved in chloroform and $20 \mu \mathrm{L}$ solution was injected over the column with a run time of about $40 \mathrm{~min}$. The following molecular weights were measured: Number-average molecular weight $\left(M_{\mathrm{n}}\right)$, 
weight-average molecular weight $\left(M_{\mathrm{w}}\right), z$-average molecular weight $\left(M_{Z}\right)$, peak molecular weight $\left(M_{\mathrm{P}}\right)$; and the molar mass dispersity (DM) were calculated [19]. Both the virgin (not aged) and the UV aged samples were analysed.

\section{Tensile test}

Tensile testing was done according to ISO 527 to determine the following values: stress at break, Young's modulus and strain at break [20]. An Instron 5565 apparatus was used and the load of the cell was $2000 \mathrm{~N}$. Crosshead speed was fixed at $10 \mathrm{~mm} \mathrm{~min}{ }^{-1}$. The virgin and the UV aged samples were tested.

\section{Results and discussion}

\section{Production of IRMM-1027 series}

A short introduction on the preparation of the LSD spikes is presented in order to better explain the sample preparation procedure and the design of the different type of experiments [21, 22]. Each year about 1200 units of IRMM-1027 series of LSD spikes are prepared to fulfil the demands for fissile material control. High purity $\mathrm{U}$ and $\mathrm{Pu}$ certified reference metals are accurately weighed and dissolved in $5 \mathrm{~mol} \mathrm{~L}^{-1} \mathrm{HNO}_{3}$. Aliquots of $2.5 \mathrm{~mL}$ of the stock solution are dispensed into individual penicillin vials by an automated system [23]. The nitrate solution in the vial containing the $\mathrm{U}$ and $\mathrm{Pu}$ is evaporated to complete dryness. As uranyl nitrate is hygroscopic and CAB sensitive for moisture uptake, the humidity in the glove box is controlled and kept below 20-25\% relative humidity. The dried $\mathrm{UO}_{2}\left(\mathrm{NO}_{3}\right)_{2}$ and $\mathrm{Pu}\left(\mathrm{NO}_{3}\right)_{6}$ are treated with a $0.7 \mathrm{~mL}$ $10 \mathrm{wt} \% \mathrm{CAB}$ solution in acetone and kept under ventilation to let the acetone evaporate on air. As the nitrates are soluble in acetone, the final product is a layer of $\mathrm{CAB}$ capturing the uranyl- and plutonium nitrates. The evaporation takes about $3 \mathrm{~h}$. The vials are then placed on a hotplate at $45-50{ }^{\circ} \mathrm{C}$ for $45 \mathrm{~min}$ to remove any solvent residues. Finally, the vials are capped and sealed in plastic bags.

\section{Thermal behaviour of the virgin CAB samples}

Figure 2 shows the DSC curves of the three CAB samples. Analysing the curves, it can be seen that with higher butyryl content the melting peak shifts towards lower temperatures. The same tendency can be observed in case of the glass transition temperatures as well (see Table 2). This is an indication that $\mathrm{CAB}$ with low butyryl content can withstand higher operational temperatures and thus is thermally more stable than one with high butyryl content.

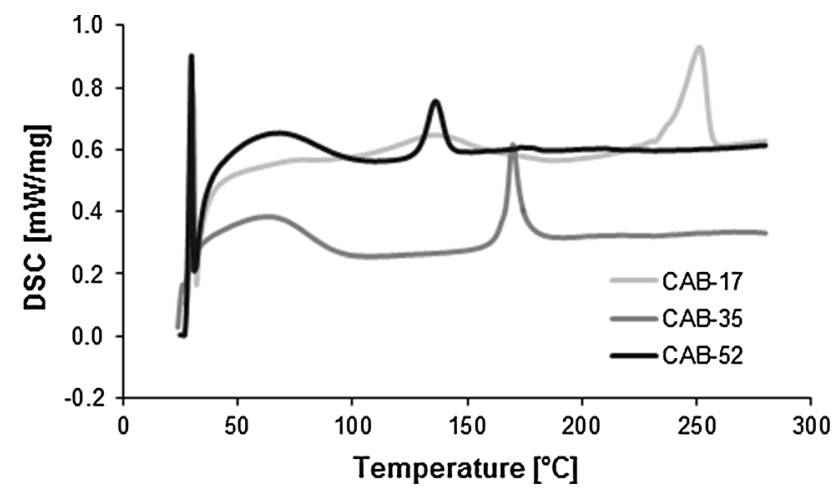

Fig. 2 DSC curves of the virgin CAB-17, CAB-35 and CAB-52 samples

In Fig. 3, the TGA and the 1st derivative of the TGA curves show that the decomposition of the different $\mathrm{CABs}$ is very similar. For CAB-17, it starts around $320^{\circ} \mathrm{C}$ while for $\mathrm{CAB}-35$ and $\mathrm{CAB}-52$ at $340{ }^{\circ} \mathrm{C}$. The thermal degradation of cellulose esters consist of a series of degradation reactions. First, dehydration occurs below $100{ }^{\circ} \mathrm{C}$, then the deacetylation and the debutyrylation take place at the beginning of the melting, and finally pyrolysis of cellulose skeleton takes place [15]. The DTG curves confirmed that there is only one main decomposition step for all $\mathrm{CAB}$ samples which is related to the degradation of the cellulose main chain. The maximum decomposition temperature was around $360-370{ }^{\circ} \mathrm{C}$ for all the samples. This implies that the difference in butyryl content does not have a significant effect on the thermal stability of the cellulose chain. At $600{ }^{\circ} \mathrm{C}$ all the material is decomposed. This temperature range is attributed to the thermal cleavage of the glycosyl units and scission of other $\mathrm{C}=\mathrm{O}$ bonds via a free radical reaction [24].

\section{Transport simulations}

The LSD spikes are transported from the JRC-Geel to the customers; therefore transport simulations were carried out to see the impact of vibrations on the $\mathrm{CAB}$ matrix. In thin films, ab initio an internal stress exists due to the film formation; the inability of the film to shrink from evaporation of the solvent and adhere to the glass at the same time; temperature changing and relative humidity [25]. These stresses have an effect on the adhesion of the coating and could lead to delamination [26]. Moreover, film defects or local imperfections such as bubbles for instance can lead

Table 2 Thermal parameters from the DSC analysis

\begin{tabular}{llll}
\hline & CAB-17 & CAB-35 & CAB-52 \\
\hline Melt peak $\left({ }^{\circ} \mathrm{C}\right)$ & 251 & 170 & 136 \\
Glass transition $\left({ }^{\circ} \mathrm{C}\right)$ & 145 & 129 & 103 \\
\hline
\end{tabular}



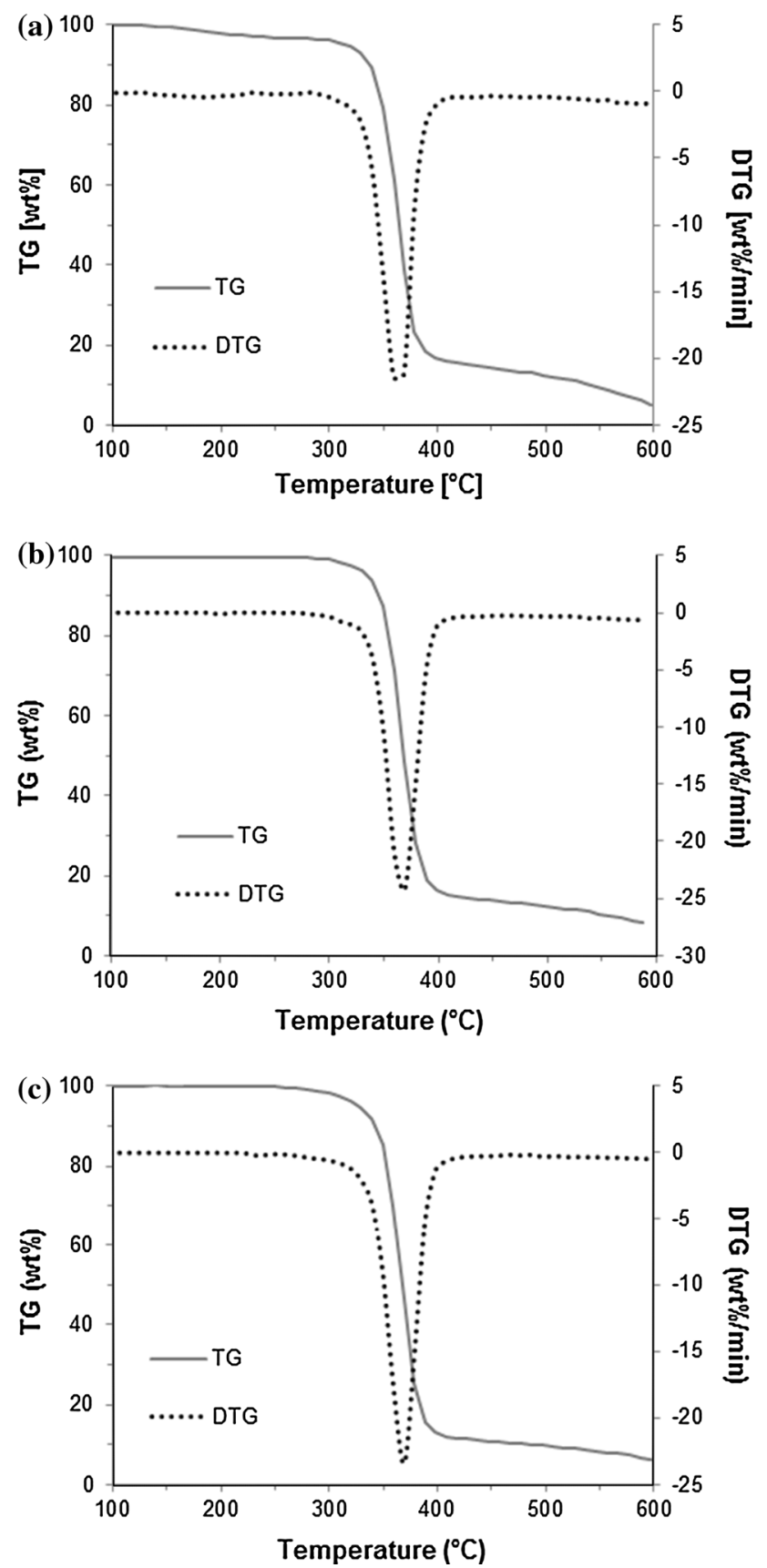

Fig. 3 TGA and DTGA curves of CAB-17, CAB-35 and CAB-52

also to stress concentrations. When a stress is introduced for instance by vibrations, all the stress will concentrate at the imperfection which can result finally in formation of cracks. This can also cause delamination via crack initiation and propagation [27]. On the one hand, it is very difficult to predict the importance of the stress contributions to the physical deterioration of the $\mathrm{CAB}$ because the chemical degradation usually disguises the effect of physical ageing. On the other hand, one still has to take into account the physical ageing as well as it has an effect on the life time of the spike material. The transport by car and the simulation of truck and airplane showed no cracks or delamination of the test samples even if they had not adhered very well to the glass vials because of the incorporation of magnesium-nitrate in the cellulose matrix (see Fig. 4).

Thus, we can conclude that vibrations caused by the transport do not have an immediate effect on the integrity of the spike; however it could have a long term effect as the vibrations could create an additional internal stress in the matrix. Our experience with the transport of actual spikes is that flaking occurs very seldom directly after the arrival of the LSD spikes: our customers reported 1 or 2 flaking samples out of 800 units sold per year and this does not happen every year. These flaking phenomena can be related to some imperfections - mainly bubbles - in the thin layer, which together with the stress that accumulates during transport leads finally to the early delamination of the material.

\section{UV light irradiation}

The xenon test is an accelerated ageing experiment meant to test the exterior durability, so to simulate outdoor weathering conditions like UV light, temperature, and humidity. In reality, the LSD spikes are never exposed to such harsh conditions; nevertheless the behaviour of the three types of $\mathrm{CAB}$ can be used to compare them and make a ranking for our application. Figure 5 shows the CAB-35 tensile samples after irradiation $1000 \mathrm{~h}$ (left) and $2000 \mathrm{~h}$ (right) in the Xenon test apparatus. As it can be seen, most of the samples after $1000 \mathrm{~h}$ of irradiationequivalent to 1 year of normal ageing-were still intact and it was possible to perform the tensile and GPC tests. The samples that were exposed for $2000 \mathrm{~h}$ were black and decomposed and the sample holder PVC bags became brittle. Tensile tests on these samples were thus not feasible to perform. The molecular weight and the molecular weight distribution contribute significantly to the properties of the material. In Table 3, the different molecular weights from the GPC measurements are summarized. For CAB-17 and CAB-35, all the values significantly decrease after $2000 \mathrm{~h}$ of exposure, for CAB-52 the degradation was so severe that there was not enough material for the GPC analysis which can be related to the initially low $M_{\mathrm{n}}$ of CAB-52: $28000 \mathrm{~g} \mathrm{~mol}^{-1}$ compared to $98000 \mathrm{~g} \mathrm{~mol}^{-1}$ of CAB-17 and to $116000 \mathrm{~g} \mathrm{~mol}^{-1}$ of CAB-35. After $1000 \mathrm{~h}$ of irradiation, the values are comparable or some of them are even a bit higher (e.g. $M_{\mathrm{w}}$ and $M_{\mathrm{Z}}$ of CAB-17 and $\mathrm{CAB}-52$ ) than of the virgin ones. This can be explained by further polymerisation of the cellulose due to the effect of UV light [28]. However, this effect diminishes after $2000 \mathrm{~h}$ when the degradation process becomes dominant. 
Fig. 4 Samples after transport simulations incorporating $\mathrm{Mg}\left(\mathrm{NO}_{3}\right)_{2}$ salt

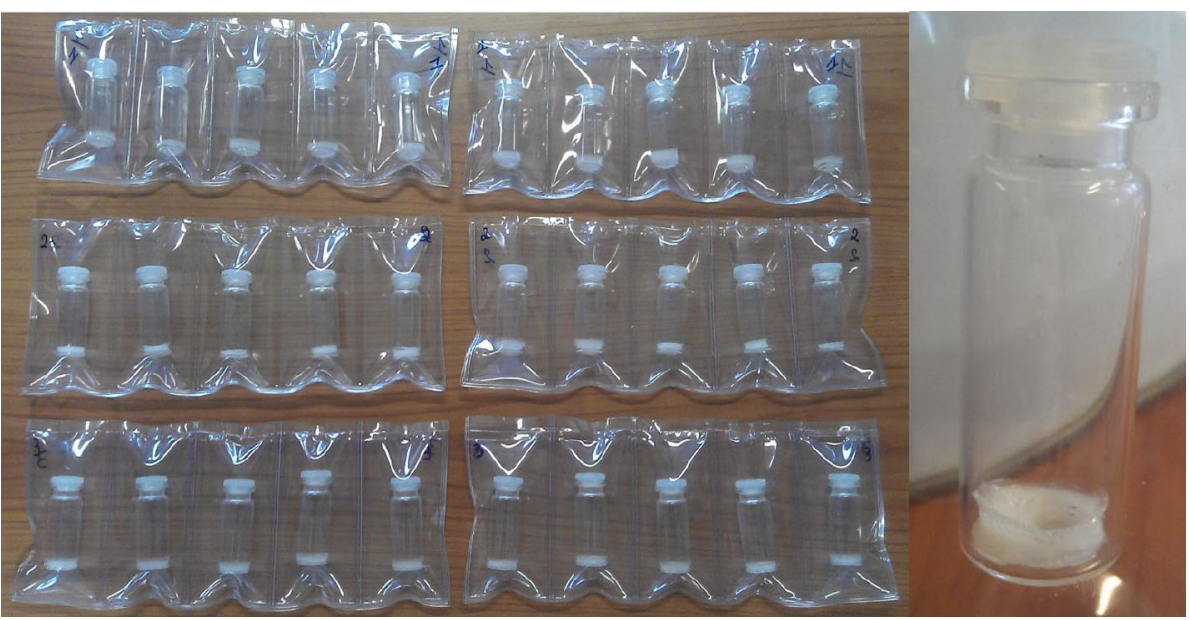

Fig. 5 Tensile test samples of CAB-35 after 1000 (left) and $2000 \mathrm{~h}$ (right) of ageing in UV light
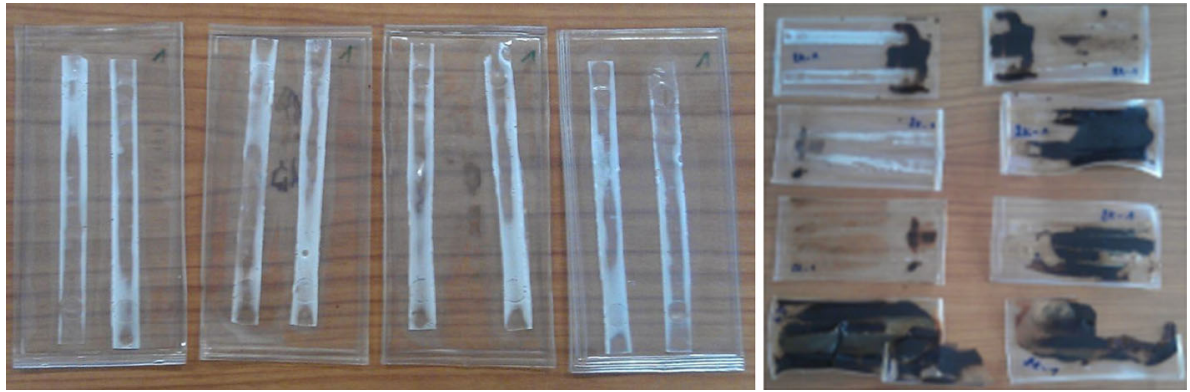

Table 3 Molecular weights from GPC measurements (only one sample was measured)

\begin{tabular}{rllll}
\hline & $M_{\mathrm{n}}\left(\mathrm{g} \mathrm{mol}^{-1}\right)$ & $M_{\mathrm{w}}\left(\mathrm{g} \mathrm{mol}^{-1}\right)$ & $M_{\mathrm{z}}\left(\mathrm{g} \mathrm{mol}^{-1}\right)$ & $M_{\mathrm{P}}\left(\mathrm{g} \mathrm{mol}^{-1}\right)$ \\
\hline CAB-17 & & & & \\
Virgin & 98,340 & 202,420 & 364,050 & 171,200 \\
$1000 \mathrm{~h}$ & 78,550 & 207,610 & 404,490 & 185,360 \\
$2000 \mathrm{~h}$ & 16,480 & 41,140 & 85,890 & 29,330 \\
CAB-35 & & & & 479,630 \\
Virgin & 115,940 & 250,140 & 479,630 & 57,610 \\
$1000 \mathrm{~h}$ & 61,150 & 176,190 & 429,650 & 42,270 \\
$2000 \mathrm{~h}$ & 22,270 & 118,750 & 389,630 & \\
CAB-52 & & & & 55,900 \\
Virgin & 27,990 & 64,020 & 116,100 & 29,790 \\
$1000 \mathrm{~h}$ & 23,000 & 69,330 & 181,180 & NA \\
$2000 \mathrm{~h}$ & $\mathrm{NA}$ & NA & NA & \\
\hline
\end{tabular}

In Fig. 6, the molar mass dispersity values are shown. The values increase with longer exposure which means that there is a big variation in chain lengths within the polymer. When structural changes occur in a polymer due to degradation, the number-average molecular weight changes as well and this determines the mechanical properties of the material [29]. The mechanical properties such as the stress at break, the Young's modulus and the strain at break with the standard deviation before and after $1000 \mathrm{~h}$ of UV ageing are summarised in Table 4. The first batch of samples of CAB-17 that were prepared for the tensile testing was placed in the Xenon test chamber. When attempting to prepare further batches, the thin film samples were deformed and curled thus it was not possible to perform tensile tests on them. Basically, CAB-17 is a more brittle material and this we have experienced during sample preparation. The reason why we could prepare the first batch successfully and the rest we could not remained unclear; therefore data are not available for the virgin samples of CAB-17. Despite that measurement data are missing on the tensile test we assume that $\mathrm{CAB}-17$ has the higher tensile strength then $\mathrm{CAB}-35$ and CAB-52 thanks to 


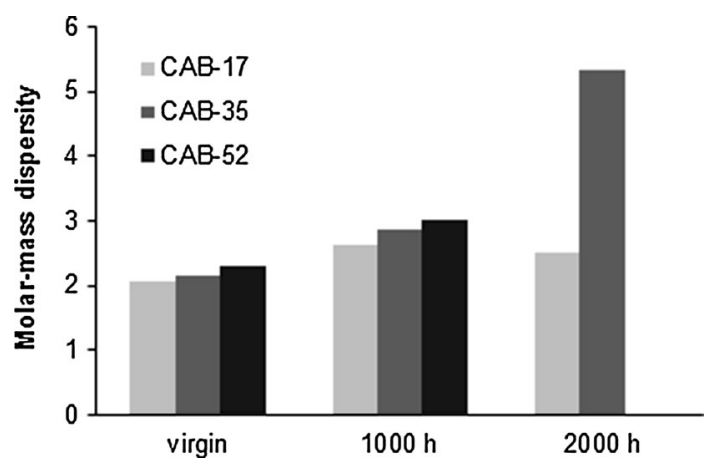

Fig. 6 Molar mass dispersity of the three $C A B$ samples-virgin and UV-aged samples

its low butyryl content and high molecular weight: $65,000 \mathrm{~g} \mathrm{~mol}^{-1}$.

It can be observed that the modulus of the non-aged and of the UV exposed samples have a tendency to decrease to approximately $50 \%$ : thanks to the ageing the mechanical strength reduces due to the chemical degradation of the polymer. Comparing the strain at break values it either does not change-for CAB-35 it is within the range of standard deviation - or in case of CAB-52 it has been even increased. This phenomenon can be explained with further polymerisation of the cellulose due to the effect of UV light. It can be stated that the higher the butyryl content, the lower the modulus and so the stiffness. This behaviour is linked to the properties of butyryl group as it causes rubber-like mechanical effects, thus gives more flexibility to the polymer. The stiffer the sample the less resistant to elastic deformation which could be accompanied with higher strain at the break and this was confirmed by our measurements.

\section{X-ray irradiation}

As the LSD spikes contain radioactive material, the absorption of the alpha and gamma radiation in the material itself has a major contribution to the deterioration of the $\mathrm{CAB}$. The $\mathrm{U}$ and $\mathrm{Pu}$ are embedded in the cellulose matrix [30] and the charged alpha particles and gamma rays can cause scission of the polymer. The main activity contributors are: $\mathrm{Pu}-239$ which is an alpha emitter and $\mathrm{Pu}$ 241 which is a beta emitter, 4 and $1.6 \mathrm{MBq}$, respectively. Ionizing radiation can either induce cross-linking within the cellulose chain [31] or can also result in degradation of cellulose based materials [16, 32] which depends on the absorbed dose, the type of radiation used and the state of matter as well. As it was not possible to investigate the original material with state of the art techniques in a glove box due to the $\mathrm{U}$ and $\mathrm{Pu}$ presence at the JRC-Geel, an irradiation experiment of the virgin $\mathrm{CAB}$ samples with $\mathrm{X}$-rays was designed and carried out at the Ghent University. The interaction of the $\mathrm{CAB}$ with $\mathrm{X}$-rays is different from the alpha particles; nevertheless the experiment still gives an indication of how the different types of $\mathrm{CAB}$ perform under exposure to ionizing radiation. There is evidence that irradiation of cellulose acetate (CA) with $\mathrm{X}$-rays resulted in gas evolution- $\mathrm{CO}, \mathrm{CO}_{2}$ and $\mathrm{H}_{2}$ - and cracks and discoloration could be observed [33]. It was also reported that CAB-35 irradiated with gamma rays resulted in a loss of ester bonds and this effect increased with increasing dose rate [11]. The three types of CAB samples were therefore irradiated in a so-called micro-XRF device for 3 days [34]. The 3 days irradiation corresponded approximately to 3 years of storage of the CRM. The $\mathrm{X}$-rays were monochromatic and the changes in the material were recorded by following the Compton and Rayleigh scattering (see Figs. 7, 8, 9).

When some structural changes occur in the polymer the density changes as well. This provides a direct evidence for the degradation of the material. As it can be seen in Fig. 7, the Compton scattering intensity slightly decreases for CAB-17 after approximately $80,000 \mathrm{~s}$ irradiation which corresponds to about a year exposure. In the right side of Fig. 7 the Compton/Rayleigh fraction shows the irradiated mass (density $\times$ thickness) of the sample. As the polymer breaks down, it is assumed that the irradiated mass changes as well. For CAB-35 and CAB-52 (Fig. 8, 9 ), no changes in the local density can be detected thus
Table 4 Tensile parameters with their standard deviations of the virgin and UV light aged samples after $1000 \mathrm{~h}$

\begin{tabular}{rlll}
\hline & Stress at break $\left(\mathrm{N} \mathrm{mm}^{-2}\right)$ & Modulus $(\mathrm{MPa})$ & Strain at break $(\%)$ \\
\hline $\begin{array}{r}\text { CAB-17 } \\
\text { Virgin }\end{array}$ & $\mathrm{NA}$ & $\mathrm{NA}$ & $\mathrm{NA}$ \\
$1000 \mathrm{~h}$ & $12.7 \pm 5.5$ & $1591.5 \pm 112.9$ & $0.89 \pm 0.25$ \\
$\mathrm{CAB}-35$ & & & \\
Virgin & $9.8 \pm 1.6$ & $1010.6 \pm 60.1$ & $1.02 \pm 0.18$ \\
$1000 \mathrm{~h}$ & $4.1 \pm 0.6$ & $588.4 \pm 84.1$ & $0.95 \pm 0.18$ \\
CAB-52 & & & \\
Virgin & $2.3 \pm 0.3$ & $409.7 \pm 97.5$ & $0.65 \pm 0.29$ \\
$1000 \mathrm{~h}$ & $2.3 \pm 0.5$ & $267.7 \pm 82.8$ & $1.01 \pm 0.09$ \\
\hline
\end{tabular}



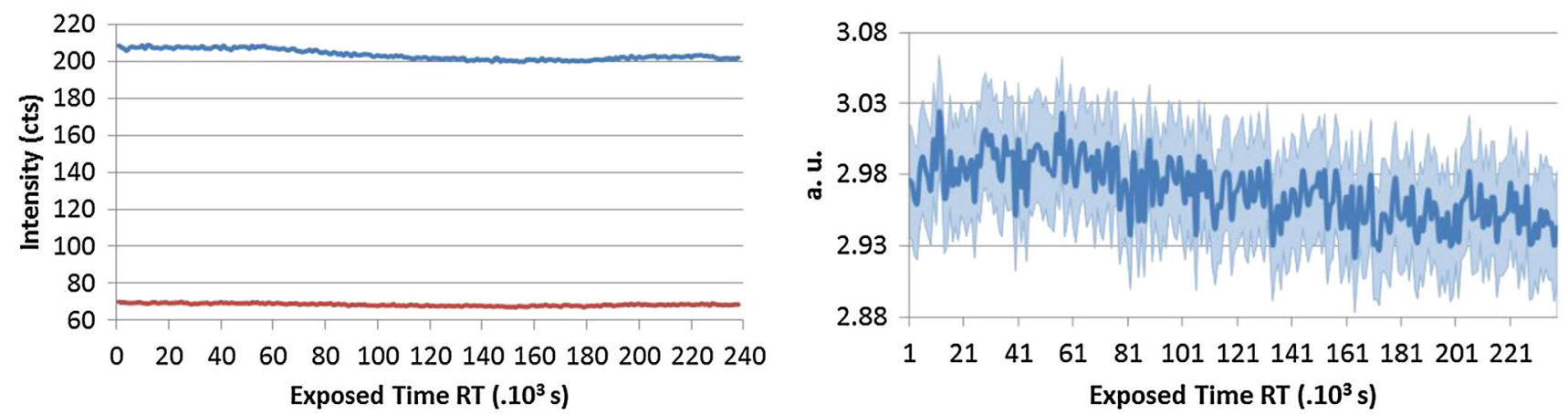

Fig. 7 CAB-17 Normalized Compton (blue or upper curve) and Rayleigh (red or lower curve) intensity changes (left) Mass changes through Compton/Rayleigh with time (right). (Color figure online)


Fig. 8 CAB-35 Normalized Compton (blue or upper curve) and Rayleigh (red or lower curve) intensity changes (left) Mass changes through Compton/Rayleigh with time (right). (Color figure online)
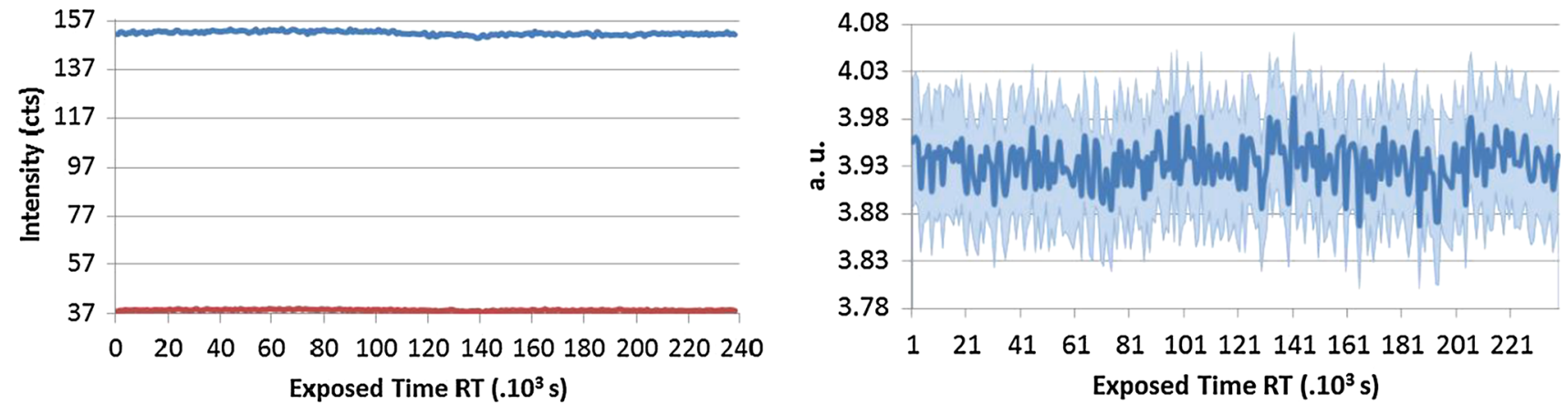

Fig. 9 CAB-52 Compton (blue or upper curve) and Rayleigh (red or lower curve) intensity changes (left) Mass changes through Compton/ Rayleigh with time (right). (Color figure online)

there is no evidence for the polymer degradation under irradiation with X-rays. At the JRC-Geel, we have experience with CAB-35 applied to the batch IRMM-1027 m, a batch that was prepared in 2009. The spikes covered with CAB-35 properly stored in an upright position and which were not exposed to vibrations due to transport, stayed intact for 5 years (Fig. 10, left hand side) while the spikes covered with $\mathrm{CAB}-17$ are already deteriorated and flaked off (Fig. 10, right hand side). This empirical experience already proved that for our specific application on LSD spikes, CAB with $35 \mathrm{wt} \%$ butyryl has a longer life time then $\mathrm{CAB}$ with $17 \mathrm{wt} \%$ butyryl substitution.
Thus, this study carried out at the JRC-Geel is line with the experiments of $\mathrm{X}$-ray irradiation confirming that $\mathrm{CAB}$ with higher butyryl content seems to be more resistant to ionizing radiation. The samples were so small that it was not possible to analyse them after the irradiation with the GPC technique to measure the molecular weights. As the long term stability of the IRMM-1027 LSD spike material is determined by the life time of the $\mathrm{CAB}$, it is very crucial to find the most suitable butyryl substitution. Therefore, further empirical studies will be carried out blending $\mathrm{CAB}-17$ and $\mathrm{CAB}-52$ with $\mathrm{CAB}-35$ and apply them on the U-Pu spikes. 


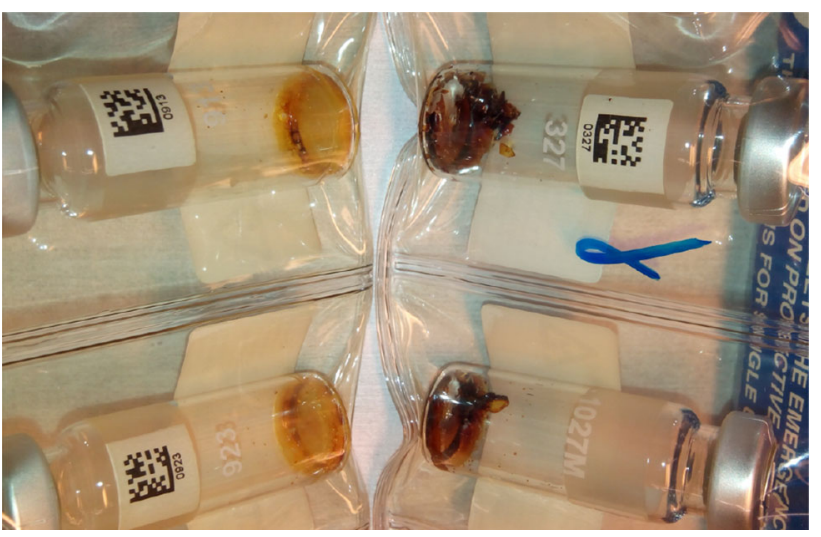

Fig. 10 CAB-35 (left) and CAB-17 (right) appereance on the IRMM$1027 \mathrm{~m}$ batch of LSD spikes after 5 years of storage

\section{Conclusions}

The long-term stability of CAB-17, CAB-35 and CAB-52 were investigated under different ageing conditions in order to select the most robust and chemically resistant $\mathrm{CAB}$ for the series of IRMM-1027 LSD spikes. Thin film samples were prepared without $\mathrm{U}$ and $\mathrm{Pu}$ and characterized before and after ageing with TGA, DSC, GPC, tensile test and via Compton and Rayleigh scattering. The samples were aged by transport, UV light, humidity, temperature and X-rays. CAB-17 showed better thermal and mechanical stability while CAB-35 and CAB-52 were more resistant against weathering and ionizing radiation. $\mathrm{CAB}-35$, which was proven at the JRC-Geel to have a long-term stability of over 5 years, therefore it was chosen as an organic matrix for the production of LSD spikes and the validity of the certificate is issued for 3 years. For the future, the results of this study give an indication that a slightly different cellulose acetate versus butyryl content together with fine tuning of the chemical procedure which will possibly allow us to prolong the validity of our certificates even beyond 3 years.

\begin{abstract}
Acknowledgments The authors would like to thank to Maarten De Groote (previously student of CPMT) for the sample preparation and the tensile test experiments, to the Polymer Chemistry Research Group for the GPC measurements, and to Jan Garrevoet (currently Deutsches Elektronen-Synchrotron, DESY Photon Science, Hamburg, Germany) for carrying out the X-ray experiments at the Ghent University, Belgium. The authors also would like to thank to Håkan Emteborg (JRC-Geel) for the idea of testing CAB with different butyryl content, to Kálmán Tóth (JRC-Geel) for his valuable contribution analysing the experimental data, and to Roger Wellum for his ideas and reviewing the manuscript of the paper.
\end{abstract}

Open Access This article is distributed under the terms of the Creative Commons Attribution 4.0 International License (http://crea tivecommons.org/licenses/by/4.0/), which permits unrestricted use, distribution, and reproduction in any medium, provided you give appropriate credit to the original author(s) and the source, provide a link to the Creative Commons license, and indicate if changes were made.

\section{References}

1. Treaty establishing the European Atomic Energy Community (Euratom), Rome, Italy (1957). http://eur-lex.europa.eu/legalcontent/EN/TXT/?uri=uriserv:xy0024

2. Treaty on the non-proliferation of nuclear weapons (NPT), United Nations, New York, (1968). https://www.iaea.org/sites/ default/files/publications/documents/infcircs/1970/infcirc140.pdf

3. De Bièvre $P$, Ingelbrecht $C$, Verbruggen A, Orea-Rocha JM, Barrandon JN (1991) Solid spikes from CBNM for input analysis. In: Proceedings of 13th annual ESARDA meeting: pp 279-232

4. Wellum R, Verbruggen A, Richter S, Aregbe Y (2010) Some consideration on the role of LSD spikes in safeguarding nuclear reprocessing plants. In: Proceeding paper of the technical meeting hosted by JNFL on large-sized dried spikes, pp 1-5

5. Boulyga S, Konegger-Kappel S, Richter S, Sangély L (2015) Mass spectrometric analysis for nuclear safeguards. J Anal At Spectrom 30:1469-1489

6. Zhao K, Penkin M, Norman C, Balsley S, Mayer K, Peerani P, Pietri C, Tapodi S, Tsutaki Y, Boella M, Renha G, Kuhn E (2012) International target values 2010 for measurement uncertainties in safeguarding nuclear materials. ESARDA Bull 48:3-24

7. Jakopič R, Buják R, Aregbe Y, Richter S, Buda R, Zuleger E (2015) Results of REIMEP-17 interlaboratory comparison for the measurement of the $\mathrm{U}$ and $\mathrm{Pu}$ amount content and isotope amount ratios in the synthetic dissolved spent nuclear fuel solution. Accred Qual Assur 20:421-429

8. Verbruggen A, Hendrickx F, Alonso A, Mayer K, De Bièvre P (1993) Solid spikes for input analysis. In: Proceedings of 15th annual ESARDA meeting: pp 277-280

9. Surugaya N, Hiyama T, Verbruggen A, Wellum R (2008) Preparation, certification and validation of a stable solid spike of uranium and plutonium coated with a cellulose derivative for the measurement of uranium and plutonium content in dissolved nuclear fuel by isotope dilution mass spectrometry. Anal Sci 24:247-252

10. Edgar KJ, Buchanan CM, Debenham JS, Rundquist PA, Seiler BD, Shelton MC, Tindall D (2001) Advances of cellulose ester performance and application. Prog Polym Sci 26:1605-1688

11. Chavan V, Kalsi PC, Nadkarni VS, Pandey AK (2010) Determination of track registration efficiency and radiation chemical yield for loss of ester bonds due to gamma rays in cellulose acetate butyrate $(\mathrm{CAB})$ nuclear track detector. J Radioanal Nucl Chem 286:181-183

12. Sigma Aldrich Catalog, Cellulose acetate butyrate avarage $\sim \mathrm{Mn}$ 70,000. http://www.sigmaaldrich.com/catalog/pro duct/aldrich/419044?lang=en\&region=BE

13. Lee H-S, Choi J-I, Kim J-H, Lee K-W, Chung Y-J, Shin M-H, Byun M-W, Shin M-G, Lee J-W (2009) Investigation on radiation degradation of carboxymethylcellulose by ionizing irradiation. Appl Radiat Isotopes 67:1513-1515

14. Xing C, Wang H, Hu Q, Xu F, Cao X, You J, Li Y (2013) Mechanical and thermal properties of eco-friendly poly (propylene carbonate)/cellulose acetate butyrate blends. Carbohydr Polym 92:1921-1927

15. Huang M-R, Li X-G (1998) Thermal degradation of cellulose and cellulose esters. J Appl Polym Sci 68:293-304

16. Ershov BG (1998) Radiation-chemical degradation of cellulose and other polysaccharides. Russ Chem Rev 67:315-334

17. Raptis K, Alonso A, Ingelbrecht $C$, Verbruggen A, Wellum $R$ (1999) The Preparation of metal spikes for IDMS of reprocessing input solutions. In: Proceedings of 21st annual ESARDA meeting, pp 598-592

18. ISO 4892-3 (2016) Plastics-Methods of exposure to laboratory light sources-Part 3: Fluorescent UV lamps. International Organization for Standardisation, Geneva 
19. Gilbert RG, Hess M, Jenkins AD, Jones RG, Kratochvíl P, Stepto RFT (2009) Dispersity in polymer science. Pure Appl Chem $81: 351-353$

20. ISO 527 (2012) Plastics-determination of tensile properties. International Organization for Standardisation, Geneva

21. Buják R, Bauwens J, Jakopič R, de Groote M, Cardon L, Aregbe Y (2013) Investigation on the long-term stability of IRMM-1027 series of large-sized dried (LSD) spikes. ESARDA Bull 49:46-48

22. Bauwens J, Verbruggen A, Wellum R, Aregbe Y, Richter S (2010) A new type of LSD spike for fissile material control. In: Proceedings of the 2nd JAPAN-IAEA workshop: pp 1-5

23. Verbruggen A, Bauwens J, Van de Steene N, Jakobsson U, Eykens R., Wellum R (2008) An automated system for the preparation of large size dried (LSD) spikes. In: Proceedings of ATALANTE 2008 P7_05: pp 1-4

24. Emsley AM, Stevens GC (1994) Kinetics and mechanisms of the low-temperature degradation of cellulose. Cellulose 1:26-56

25. Perera D (1996) On adhesion and stress in organic coatings. Prog Org Coat 28:21-23

26. Perera D (2003) Physical ageing of organic coatings. Prog Org Coat 47:61-76

27. Jr Wicks Z W, Jones FN, Pappas SP, Wicks DA (2007) Organic coatings science and technology, 3rd edn. Wiley, New Jersey
28. Mishra S, Sen G, Dey KP, Rani GU (2015) Synthesis and applications of grafted carboxymethyl cellulose: a review (Chap. 21). In: Thakur VK (ed) Cellulose-based graft copolymers: structure and chemistry. CRC Press, Boca Raton, pp 475-496

29. Meijer HEH, Govaert LE (2005) Mechanical performance of polymer systems: the relation between structure and properties. Prog Polym Sci 30:915-938

30. Popescu I-C, Filip p, Humelnicu D, Humelnicu I, Scott TB (2013) Removal of uranium (VI) from aqueous system by nanoscale zero-valent iron particles suspended in carboxy-methyl cellulose. J Nucl Mater 443:250-255

31. Fekete T, Borsa J, Takács E, Wojnárovits L (2014) Synthesis of cellulose derivative based superabsorbent hydrogels by radiation induced crosslinking. Cellulose 21:4157-4165

32. Swallow AJ (1960) Radiation chemistry of organic compounds. Pergamon Press, Oxford

33. Winogradoff NN (1950) X-ray irradiation of cellulose acetate. Nature 165:72

34. Adams F, Vekemans B, Silversmit G, De Samber B, Vincze L (2011) Microscopic X-ray fluorescence analysis with synchrotron radiation sources. In: Vértes A, Nagy S, Klencsár Z, Lovas GR, Rösch F (eds) Handbook of nuclear chemistry, vol 2. Springer, Berlin, pp 1738-1759 